\title{
The effect of citrus-derived oil on bovine blood neutrophil function and gene expression in vitro
}

\author{
M. Garcia, ${ }^{*}$ T. H. Elsasser,† D. Biswas, ${ }^{*}$ and K. M. Moyes*1 \\ *Department of Animal and Avian Sciences, University of Maryland, College Park 20742 \\ †USDA, Agricultural Research Service, Growth Biology Laboratory, Beltsville, MD 20705
}

\begin{abstract}
Research on the use of natural products to treat or prevent microbial invasion as alternatives to antibiotic use is growing. Polymorphonuclear leukocytes (PMNL) play a vital role with regard to the innate immune response that affects severity or duration of mastitis. To our knowledge, effect of cold-pressed terpeneless Valencia orange oil (TCO) on bovine PMNL function has not been elucidated. Therefore, the objective of this study was to investigate the effect of TCO on bovine blood PMNL chemotaxis and phagocytosis capabilities and the expression of genes involved in inflammatory response in vitro. Polymorphonuclear leukocytes were isolated from jugular blood of 12 Holstein cows in midlactation and were incubated with 0.0 or $0.01 \% \mathrm{TCO}$ for $120 \mathrm{~min}$ at $37^{\circ} \mathrm{C}$ and $5 \% \mathrm{CO}_{2}$, and phagocytosis (2 $\times 10^{6}$ PMNL) and chemotaxis $\left(6 \times 10^{6}\right.$ PMNL) assays were then performed in vitro. For gene expression, RNA was extracted from incubated PMNL $\left(6 \times 10^{6}\right.$ PMNL), and gene expression was analyzed using quantitative PCR. The supernatant was stored at $-80^{\circ} \mathrm{C}$ for analysis of tumor necrosis factor- $\alpha$. Data were analyzed using a general linear mixed model with cow and treatment (i.e., control or TCO) in the model statement. In vitro supplementation of $0.01 \%$ of TCO increased the chemotactic ability to IL- 8 by $47 \%$; however, migration of PMNL to complement 5a was not altered. Treatment did not affect the production of tumor necrosis factor- $\alpha$ by PMNL. Expression of proinflammatory genes (i.e., SELL, TLR4, IRAK1, TRAF6, and LYZ) coding for proteins was not altered by incubation of PMNL with TCO. However, downregulation of TLR2 [fold change $(\mathrm{FC}=$ treatment $/$ control $)=-2.14]$, NFKBIA $(\mathrm{FC}=$ 1.82), IL1B $(\mathrm{FC}=-2.16)$, TNFA $(\mathrm{FC}=-9.43)$, and SOD2 (FC $=-1.57)$ was observed for PMNL incubated with TCO when compared with controls. Interestingly,
\end{abstract}

Received June 4, 2014.

Accepted October 20, 2014.

${ }^{1}$ Corresponding author: kmoyes@umd.edu expression of $I L 10$, a well-known antiinflammatory cytokine, was also downregulated $(\mathrm{FC}=-3.78)$, whereas expression of $I L 8(\mathrm{FC}=1.93)$, a gene coding for the cytokine IL-8 known for its chemotactic function, tended to be upregulated in PMNL incubated with TCO. Incubation of PMNL with TCO enhanced PMNL chemotaxis in vitro. The expression of genes involved in the inflammatory response was primarily downregulated. Results showed that $0.01 \%$ TCO did not impair the function of PMNL in vitro. Future studies investigating the use of TCO as an alternative therapy for treatment of mastitis, including dose and duration, for cows during lactation are warranted.

Key words: citrus oil, Holstein cow, bovine neutrophil

\section{INTRODUCTION}

The economic losses due to mastitis in the United States exceed $\$ 2$ billion annually (Nickerson and Oliver, 2014). Mastitis, an inflammation of the mammary gland, is usually associated with the presence of a pathogen such as Escherichia coli, Klebsiella spp., Streptococcus spp., and Staphylococcus spp. (Kehrli and Shuster, 1994). During mastitis, circulating neutrophils, also known as PMNL, are of key importance in controlling the severity and duration of mastitis (Burvenich et al., 2007). During inflammation, PMNL are the most predominant cell type in the mammary gland, accounting for approximately $95 \%$ of somatic cell population (Kehrli and Shuster, 1994), and are, therefore, of critical importance for resolution of mastitis. Antibiotics to treat mastitis have been extensively used in the past 60 yr (Plastridge, 1958). However, growing consumer concerns regarding antibiotic use have led to the examination of alternative strategies for controlling mastitis while reducing the use of antibiotics on-farm (Bannantine et al., 2013).

Citrus oils, or fractions thereof, have been traditionally used as flavoring agents in foods, and it has frequently been noted that many possess antimicrobial properties (Smith-Palmer et al., 1998; Alzoreky and Nakahara, 2003; Muthaiyan et al., 2012a,b). Citrus essential oils have been part of the human diet for hundreds 
of years. Therapeutic use of a variety of essential oils as either individual compounds or mixtures has been satisfactorily evaluated to inhibit the activity (growth inhibition) of Staphylococcus strains and E. coli (Fratini et al., 2014). Citrus essential oils are complex mixtures of volatile and nonvolatile compounds. The volatile compounds are a mixture of monoterpene and sesquiterpene hydrocarbons and their oxygenated derivatives (Fisher and Phillips, 2008). Removal of the terpene fraction from essential oils, which are readily oxidized when exposed to air, is performed by fractional distillation, by extraction of the oxygenated compounds with diluted alcohol or other solvents, or by combination of these methods resulting in significant reduction of the limonene fraction (Kirchner and Miller, 1952). Studies evaluating the therapeutic use of citrus essential oils in ruminants are very limited and are more focused on its antibacterial effect in reducing pathogen population in feces (Jacob et al., 2009; Callaway et al., 2011).

Cold-pressed terpeneless Valencia orange oil (TCO) contains limited amounts of the essential-oil limonene $(0.3 \%)$ and is rich in linalool $(20.2 \%)$, decanal $(18 \%)$, and geranial (9.1\%; Nannapaneni et al., 2009). This product is more stable and contains most of the odor and flavor of the original oil (Kirchner and Miller, 1952). Several in vitro studies, using different concentrations of TCO, reported that TCO inhibits the growth of a wide range of microbes such as Mycobacterium tuberculosis and Mycobacterium bovis (Crandall et al., 2012), E. coli O157:H7 (Nannapaneni et al., 2008), Campylobacter jejuni and Campylobacter coli (Nannapaneni et al., 2009), Staphylococcus aureus (Muthaiyan et al., 2012b), and different Listeria strains (Shannon et al., 2011; Muthaiyan et al., 2012b). Other studies have evaluated the antimicrobial effect of TCO on growth reduction of $C$. jejuni and $C$. coli in retail chicken legs and thighs (Nannapaneni et al., 2009), Samonella ssp. and E. coli O157:H7 in beef meat (Pittman et al., 2011), and Staph. aureus in keratinocytes (Muthaiyan et al., 2012a). To our knowledge, no study has evaluated the effect of TCO as an alternative therapy to control mastitis in dairy cows. Because of their vital role in controlling mastitis, examining the effect of TCO on PMNL function will identify the role of TCO on the host response that may affect the severity and duration of mastitis. Therefore, the objective of this study was to investigate the effect of TCO on bovine blood PMNL chemotaxis and phagocytosis capabilities in vitro and the expression of genes involved in the inflammatory response of PMNL. Results will identify the effect of TCO on PMNL inflammatory response and advance our knowledge regarding its potential use as an alternative therapy for mastitis in dairy cows.

\section{MATERIALS AND METHODS}

\section{Animals}

All procedures involving the use of live animals were approved in accordance with the regulations and guidelines set forth by the USDA Beltsville Animal Care and Use Committee. Twelve Holstein cows in mid-lactation (129 \pm 22 DIM; 7 primiparous and 5 multiparous) were used for this study. All cows were free of clinical signs of disease before the study. Cows were housed and fed in freestalls, had free access to water, and were milked twice daily at 0800 and $1800 \mathrm{~h}$. Cows were fed a TMR to provide $100 \%$ of NRC requirements daily at $1100 \mathrm{~h}$.

Jugular blood $(\sim 150 \mathrm{~mL})$ was collected from each cow after the morning milking and before the morning feeding. Blood was collected into evacuated tubes containing acid-citrate dextrose (Fisherbrand, Thermo Fisher Scientific Inc., Pittsburgh, PA), inverted to mix, and placed on ice. Blood samples were processed within $1 \mathrm{~h}$ of collection.

\section{Isolation of PMNL}

Polymorphonuclear leukocytes were isolated according to procedures described by Moyes et al. (2009), with minor modifications. Blood was transferred to 15-mL conical tubes (Fisherbrand, Thermo Fisher Scientific Inc.) and centrifuged (model 5810R, Eppendorf, Hauppauge, NY) for $20 \mathrm{~min}$ at $1,000 \times g$ at $4^{\circ} \mathrm{C}$. After centrifugation, the plasma, buffy coat, and one-third of the red blood cells were discarded. The remaining cells were transferred to a 50-mL conical tube (Fisherbrand, Thermo Fisher Scientific Inc.), and the cell suspension was lysed with $18 \mathrm{~mL}$ of ice-cold deionized water. The cell suspension was inverted gently for no longer than $45 \mathrm{~s}$, and isotonicity was restored by addition of $2 \mathrm{~mL}$ of 10× PBS (pH 7.4; Sigma-Aldrich, St. Louis, MO). The solution was then centrifuged for $10 \min (200 \times g$ at $4^{\circ} \mathrm{C}$ ) and the supernatant decanted. The pellet was washed with $20 \mathrm{~mL}$ of endotoxin-free, calcium- and magnesium-free Hanks' balanced salt solution (CMFHBSS, Sigma-Aldrich) and centrifuged for 5 min $(850$ $\times g$ at $4^{\circ} \mathrm{C}$ ). If needed, cells were lysed for a second time by adding $1.8 \mathrm{~mL}$ of ice-cold deionized water followed by $200 \mu \mathrm{L}$ of $10 \times$ PBS and $20 \mathrm{~mL}$ of CMF-HBSS and centrifuged for $5 \mathrm{~min}\left(850 \times g\right.$ at $\left.4^{\circ} \mathrm{C}\right)$. Cells were washed twice with $20 \mathrm{~mL}$ of CMF-HBSS and centrifuged for $5 \mathrm{~min}\left(850 \times g\right.$ at $\left.4^{\circ} \mathrm{C}\right)$. After the final wash, the pellet was resuspended in $1 \mathrm{~mL}$ of CMF-HBSS, and PMNL concentrations were measured using a TC20 automated cell counter (Bio-Rad Laboratories Inc., Hercules, CA). Using the trypan blue (0.1\%, Bio-Rad Laboratories Inc.) exclusion method (Freshney, 1987), 
the average viability of PMNL was 92.3\%. Cell differentials were determined microscopically on cytospin preparations using a commercially available hematology staining kit (Hema-Fast 3-Step Hematology Staining Kit; Fisherbrand, Thermo Fisher Scientific Inc.). Results indicated that $88.5 \%$ of isolated cells were PMNL.

\section{Citrus Essential-Oil Product and Cytotoxicity}

Commercially available TCO was obtained from the Firmenich Citrus Center (Safety Harbor, FL). Citrus essential oils are complex mixtures of volatile (85-99\%) and nonvolatile compounds (1-15\%). The volatile compounds are a mixture of monoterpene and sesquiterpene hydrocarbons and their oxygenated derivatives including aldehydes, ketones, acids, alcohols, and esters (Fisher and Phillips, 2008). Moufida and Marzouk (2003) reported that limonene $(\sim 88 \%)$ is the major component of the sweet orange oil, whereas linalool is found in minimal proportions $(0.02 \%)$. However, removal of the terpene fraction drastically reduces the proportion of limonene (Kirchner and Miller, 1952). Nannapaneni et al. (2009) listed linalool (20.2\%), decanal (18\%), and geranial $(9.1 \%)$ as the main compounds for TCO grown in Florida, whereas limonene is only present at $0.3 \%$.

Cytotoxicity. The cytotoxicity of TCO on PMNL was determined in vitro. Polymorphonuclear leukocytes $\left(\sim 4 \times 10^{4}\right.$ cells in $200 \mu \mathrm{L}$ of CMF-HBSS), isolated from 9 cows (134 DIM), were added to a sterile, round-bottom, 96-well plate (Fisherbrand, Thermo Fisher Scientific Inc.) according to methods previously described (Muthaiyan et al., 2012a) with modifications for PMNL cytotoxicity. Briefly, plates were centrifuged (model 5810R, Eppendorf) at $23^{\circ} \mathrm{C}$ at $1,000 \times g$ for $10 \mathrm{~min}$ and supernatant was discarded. The pellet was resuspended with $200 \mu \mathrm{L}$ of CMF-HBSS containing a fixed amount $(0.1 \%)$ of dimethyl sulfoxide (DMSO, BDH chemicals, VWR International, Philadelphia, PA) and either $0,0.005,0.01$, or $0.1 \%$ of TCO. Cells were incubated (Binder Inc., Bohemia, NY) at $37^{\circ} \mathrm{C}$ and $5 \%$ $\mathrm{CO}_{2}$ for $2 \mathrm{~h}$. Cells were centrifuged at room temperature at $1,000 \times g$ for $10 \mathrm{~min}$, and supernatant was discarded after centrifugation. Cells were reconstituted again with $200 \mu \mathrm{L}$ of CMF-HBSS and centrifuged at $23^{\circ} \mathrm{C}$ at $1,000 \times g$ for $10 \mathrm{~min}$. After centrifugation, cells were resuspended in $50 \mu \mathrm{L}$ of 3-(4,5-dimethylthiazol-2-yl)-2,5diphenyltetrazolium bromide $(5 \mathrm{mg} / \mathrm{mL})$ reconstituted in $1 \times$ PBS. Cells treated with 3-(4,5-dimethylthiazol2-yl)-2,5-diphenyltetrazolium bromide were incubated for $2 \mathrm{~h}$ at $37^{\circ} \mathrm{C}$ and $5 \% \mathrm{CO}_{2}$. After incubation, plates were centrifuged at $1,000 \times g$ for $10 \mathrm{~min}, 150 \mu \mathrm{L}$ of DMSO was added to each well, and formed crystals were dissolved by vigorously pipetting up and down.
Finally, plates were incubated at room temperature at a constant rotation for $15 \mathrm{~min}$, and absorbance was measured at $570 \mathrm{~nm}$. Relative cytotoxicity was calculated as 1 - (absorbance of treated PMNL/absorbance of control PMNL). Supplemental Figure S1 (http:// dx.doi.org/10.3168/jds.2014-8450) depicts the relative expression of the different doses of TCO compared with the control (0\% TCO and $0.1 \%$ DMSO). The assay demonstrated that $0.01 \%$ of TCO or less in $0.1 \%$ DMSO was not toxic $(P>0.10)$ to the surveillance of PMNL, whereas a dose of $0.1 \%$ TCO was toxic $(P<$ 0.01 ). Therefore, the dose of $0.01 \%$ of TCO in $0.1 \%$ DMSO was selected for further analysis.

Treatment Preparation. Stock of TCO (commercial product) was diluted at $10 \%$ concentration with DMSO. A further dilution was performed using CMFHBSS to reach a working concentration of $0.1 \%$ TCO. Incubations were performed in $50-\mathrm{mL}$ conical tubes (Fisherbrand, Thermo Fisher Scientific Inc.). Cell suspensions containing $2 \times 10^{6} \mathrm{PMNL} / \mathrm{mL}$ (phagocytosis assay; final volume of $4.0 \mathrm{~mL}), 6 \times 10^{6} \mathrm{PMNL} / \mathrm{mL}$ (chemotaxis assay; final volume of $1.0 \mathrm{~mL}$ ), or $6 \times 10^{6}$ $\mathrm{PMNL} / \mathrm{mL}$ [quantitative PCR (qPCR); final volume of $1.0 \mathrm{~mL}$ ] were added using RPMI $/ 5 \%$ heat-inactivated fetal bovine serum (FBS; Sigma-Aldrich). For all assays, working solutions of either control $(0.0 \%$ TCO) or TCO $(0.01 \%$ TCO $)$ were added to each tube. All PMNL were incubated for $120 \mathrm{~min}$ at $37^{\circ} \mathrm{C}, 95 \%$ relative humidity, and $5 \% \mathrm{CO}_{2}$ using a constant rotator.

After incubation, PMNL chemotaxis and phagocytosis capabilities were assessed as described below. For qPCR analysis, $1.0 \mathrm{~mL}$ of cell suspensions was transferred into 2.0-mL RNase-free tubes (Fisherbrand, Thermo Fisher Scientific Inc.) and centrifuged $\left(10,000 \times g\right.$ at $4^{\circ} \mathrm{C}$ for $\left.2 \mathrm{~min}\right)$. The spent media were collected and stored at $-80^{\circ} \mathrm{C}$ for analysis of tumor necrosis factor- $\alpha$ (TNF- $\alpha)$, whereas the cell pellet was washed twice with $1.0 \mathrm{~mL}$ of $1 \times$ PBS and $1.0 \mathrm{~mL}$ of TRIzol Reagent (Invitrogen, Carlsbad, CA) with $1 \mu \mathrm{L}$ of linear acrylamide (Ambion Inc., Austin, TX) added. Polymorphonuclear leukocytes were homogenized (VDI 25 Homogenizer, VWR International) and stored at $-80^{\circ} \mathrm{C}$ until further analysis.

\section{PMNL Chemotaxis}

Chemoattractants used in this experiment included human IL-8 (Sigma-Aldrich) and recombinant human complement 5a (C5a; Sigma-Aldrich). Chemoattractants were adjusted to a final concentration of $100 \mathrm{ng} /$ $\mathrm{mL}$ and $10^{-9} M$ for IL-8 and C5a, respectively, using $1 \times$ PBS. In triplicate, $600 \mu \mathrm{L}$ of each chemoattractant was added to the bottom wells of a 24 -flat bottom well plate 
(Fisherbrand, Thermo Fisher Scientific Inc.). Filters were added (pore size of $5.0 \mu \mathrm{m}$; 6.5 -mm diameter; 0.3$\mathrm{cm}^{2}$ growth area; Fisherbrand, Thermo Fisher Scientific Inc.) to the top of each well. A total of $100 \mu \mathrm{L}$ of cell suspension adjusted to $6 \times 10^{6} \mathrm{PMNL} / \mathrm{mL}$ with RPMI1640 (Sigma-Aldrich Co.) containing 5\% FBS (SigmaAldrich Co.), and previously incubated with treatments (control or TCO), was added to the top of the filter. Plates were incubated for $90 \mathrm{~min}$ at $37^{\circ} \mathrm{C}, 5.0 \% \mathrm{CO}_{2}$, and $95 \%$ relative humidity. Following incubation, the filter was washed vigorously with $200 \mu \mathrm{L}$ of CMF-HBSS twice, and the filter was removed. The total number of PMNL migrated was counted using a TC-20 automated cell counter (Bio-Rad Laboratories Inc.).

\section{PMNL Phagocytosis}

Phagocytosis was performed according to procedures described by Moyes et al. (2009). Briefly, before incubation fluorescent beads (Fluoresbrite yellow-green Carboxylate 1.75- $\mu \mathrm{m}$ Microspheres; PolySciences, Warrington, $\mathrm{PA}$ ) were first precoated with heat-inactivated FBS $(250 \mu \mathrm{L}$ of FBS per $1 \mu \mathrm{L}$ of beads; Sigma-Aldrich Co.), and the mixture was protected from the light and incubated at room temperature for $45 \mathrm{~min}$. After TCO incubation above, $1.0 \mathrm{~mL}$ of PMNL $\left(2 \times 10^{6}\right)$ was transferred into four 5 -mL polystyrene round-bottomed tubes (Becton Dickinson Labware, Franklin Lakes, NJ). To each tube, $100 \mu \mathrm{L}$ of the FBS-coated beads was added to obtain a 10:1 ratio (beads:PMNL). Samples were run in duplicate and incubated for $2 \mathrm{~h}$ at $37^{\circ} \mathrm{C}, 5 \% \mathrm{CO}_{2}$, and $95 \%$ relative humidity and then centrifuged for 5 $\min \left(1,000 \times g\right.$ at $\left.4^{\circ} \mathrm{C}\right)$. The pellets were washed in 1 $\mathrm{mL}$ of CMF-HBSS and fixed with $400 \mu \mathrm{L}$ of $4 \%$ paraformaldehyde (Sigma-Aldrich Co.). Samples were stored at $4^{\circ} \mathrm{C}$ and protected from light until analysis $(\sim 1-2 \mathrm{~d})$ for percentage phagocytosis using an XL Flow Cytometer (Beckman Coulter, Fullerton, CA). The PMNL populations were gated by forward scatter and side scatter. Data were collected on 20,000 events per sample in the gate set for bovine PMNL, and percentage fluorescence was used as the quantitative index of PMNL response. Phagocytosis by PMNL was expressed as the total percentage of PMNL engulfing one or more beads.

\section{TNF- $\alpha$ Assay}

The spent media collected after $2 \mathrm{~h}$ incubation of PMNL with treatments was analyzed for concentration of TNF- $\alpha$ using a bovine-TNF- $\alpha$ commercial kit (VetSet Elisa Development Kit; Kingfisher Biotech Inc., St. Paul, MN) following the manufacturer's protocol. Stan- dards were prepared with $4 \%$ bovine serum albumin in PBS, and samples were diluted to $90 \%$ concentration with the same standard diluents $(4 \%$ bovine serum albumin in PBS). Samples were run in duplicate. The intraassay coefficient of variation was $2.1 \%$.

\section{RNA Isolation, cDNA Synthesis, and Quantitative Reverse-Transcription PCR (qPCR)}

A subset of 6 cows (4 primiparous, 2 multiparous) were randomly selected for gene-expression analysis. Specific details for total RNA isolation and quality evaluation, cDNA synthesis, primer selection and efficiency evaluation, and $\mathrm{qPCR}$ are found in the Supplemental Materials (http://dx.doi.org/10.3168/jds.2014-8450). Purity of extracted RNA was calculated by absorbance ratio of 260/280 measured using a NanoVue Plus (GE Healthcare, Piscataway, NJ) and averaged 1.8. Integrity of RNA was measured by the RNA quality indicator number using a Experion bioanalyzer (Bio-Rad Laboratories Inc.) and averaged 7.6. Primer sequences and accession number are presented in Supplemental Table S1 (http://dx.doi.org/10.3168/jds.2014-8450). Primer and $\mathrm{qPCR}$ validation detailing the slope, intercept, and $\mathrm{R}^{2}$ of the dilution curve as well as efficiency are found in Supplemental Table S2 (http://dx.doi.org/10.3168/ jds.2014-8450). The quantification-cycle (Cq) values from target genes were normalized by the geometric mean of 3 (GAPDH, GOLGA5, and OSBPL) out of 4 candidate target genes that were previously verified as suitable reference genes in bovine tissue (JanovickGuretzky et al., 2007; Kadegowda et al., 2009; Moyes et al., 2010). These 3 reference genes were selected based in their lower $\mathrm{M}$ value as recommended by the genorm analysis $(\mathrm{M}<0.74)$ using the Biogazelle $\mathrm{q}^{+}$software (Biogazelle NV, Zwijnaarde, Belgium) and based on the work of Vandesompele et al. (2002).

The qPCR results, given as $\mathrm{Cq}$ values for each transcript, were analyzed using the $2^{-\Delta \Delta \mathrm{Cq}}$ method (Livak and Schmittgen, 2001). Briefly, the Cq of each target gene was calculated and normalized by the geometric mean of the 3 selected reference genes to generate delta $\Delta \mathrm{Cq}$ values. The $\Delta \mathrm{Cq}$ values of control samples $(\mathrm{n}=6)$ were averaged and subtracted from each $\Delta \mathrm{Cq}$ value of the TCO samples $(\mathrm{n}=6)$ to generate the $\Delta \Delta \mathrm{Cq}$. The $\Delta \Delta \mathrm{Cq}$ values were linearized, to give the fold change (FC) value, using the formula $2^{-\Delta \Delta \mathrm{Cq}}$. Then, a positive and a negative $\mathrm{FC}$ value indicate an upregulation and downregulation in the mRNA expression of a given gene by TCO with respect to control, respectively. General description of the main biological function of the analyzed genes can be found in Supplemental Table S3 (http://dx.doi.org/10.3168/jds.2014-8450). 


\section{Statistical Analysis}

Results for the phagocytosis, chemotaxis, and gene expression $\left(2^{-\Delta \Delta \mathrm{Cq}}\right)$ assays were $\log _{10}$ transformed for statistical analysis. The PROC MIXED procedure of SAS (SAS/STAT version 9.2; SAS Institute Inc., Cary, NC) was used for statistical analysis. Separation of least squares means, for significant effects, was accomplished using the Tukey's option within the MIXED procedure of SAS. The main effect of parity and the interaction of parity $\times$ treatment were not significant $(P>0.05)$ for all variables; therefore, parity was not included in the final model. For analysis of cytotoxicity, the class variables included cow and treatment (i.e., control, $0.05,0.01$, or $0.1 \%$ of TCO). For chemotaxis, the class variables included cow, treatment (i.e., control or $0.01 \%$ TCO), and chemoattractant (i.e., IL-8 or C5a), and the model was run by chemoattractant. For phagocytosis, TNF- $\alpha$, and gene expression, the class variables included cow and treatment (i.e., control or TCO). The models were used to determine the effect of TCO on bovine blood PMNL response in vitro, using the following statistical model: $Y_{i j}=\mu+C_{i}+T_{j}$ $+\varepsilon_{i j}$, where $Y_{i j}$ is the dependent variable for the $i$ th cow for the $j$ th treatment, $\mu$ is overall mean, $C_{i}$ is the fixed effect of cow ( cow $=1,2, \ldots, n), T_{j}$ is the fixed effect of treatment, and $\varepsilon_{i j}$ is the residual error. For all models, the degrees of freedom were estimated with the Kenward-Roger specification in the model statement. The effect of cow was removed from the model if not significant $(P>0.25)$. Statistical differences were declared as significant and highly significant at $P<$ 0.05 and $P<0.01$, respectively. Trends toward significance are discussed at $0.05<P<0.10$. The $\log _{10}$ least squares means were back-transformed, and data are presented as least squares means and confidence interval for presentation in tables and figures.

\section{RESULTS AND DISCUSSION}

Neutrophils are the most abundant nonspecific leukocytes in blood and are actively recruited to the site of infection, such as mammary gland during mastitis (Sordillo, 2005). In the healthy mammary gland, the most abundant somatic cells are macrophages and lymphocytes, with very few PMNL (Kehrli and Shuster, 1994; Bannantine et al., 2013). However, during mastitis, PMNL migrate from the blood to the mammary gland and become the predominant somatic cells in milk (>95\%, Kehrli and Shuster, 1994).

Phagocytosis is one of the hallmarks of PMNL function, and incubation of PMNL with TCO did not affect the ability of PMNL to phagocytose in vitro (14.2 vs.
$15.9 \%$ for control and TCO, respectively, Figure 1). These results indicate that TCO does not impair PMNL function. Recruitment of PMNL to the mammary gland initiates a multistep adhesion cascade involving L-selectin coded by the gene $S E L L$ in PMNL (Williams et al., 2011; Mayadas et al., 2014). The migration process of PMNL is aided by the orchestrated action of chemoattractants, such as IL-8 and C5a, released by resident macrophages and mammary epithelial cells (Burvenich et al., 2003; Paape et al., 2003). This migration process, also known as chemotaxis, is still not fully understood, even though different hypotheses and mechanisms have been postulated. Among the most accepted mechanism is the hierarchical multistep migration capacity postulated by Foxman et al. (1997) indicating the preference of PMNL for end-target chemoattractants such as C5a instead of intermediate chemokines such as IL-8. This mechanism was complemented recently by Byrne et al. (2014) postulating that PMNL can migrate back and forth in an oscillatory manner when confronted with different chemoattractant signals to finally migrate to the sites of infection. Therefore, L-selectin expression is influenced by IL- 8 and C5a for adherence of PMNL to the endothelial wall (Paape et al., 2003). In the current study, chemotactic ability of PMNL by IL- 8 in vitro was improved $(P=0.03)$ by $47 \%$ when PMNL were incubated with TCO (Figure 2A), whereas chemotactic activity due to C5a did not differ because of treatment (Figure 2B). However, expression of SELL was not affected by TCO $(\mathrm{FC}=-1.20$, Table 1$)$. Interestingly, expression of $I L 8$ tended $(P=0.08)$ to be upregulated by TCO $(\mathrm{FC}=1.93)$, which may indicate that greater expression of $I L 8$ increased the synthesis of IL-8, and this enhanced the observed increased chemotaxis ability of PMNL incubated with TCO. However, most studies evaluating the use of different citrus essential oils (Hirota et al., 2010; Kummer et al., 2013) reported reduction of migration ability of rodent PMNL in response to different chemokines including IL-8. This response may be dose dependent where lower concentrations do not alter migration of PMNL (Caldefie-Chézet et al., 2006; Kacem and Meraihi, 2009). For the current study, incubation of PMNL with $0.01 \%$ TCO did not impair PMNL ability to migrate. Regardless, increased expression of IL8 was unexpected based on the downregulation of other proinflammatory genes (see below) and results from others (Hart et al., 2000; Juergens et al., 2004).

Bovine TLR-2 and TLR-4 generally mediate responses to gram-positive (i.e., Streptococcus spp.) and gram-negative (i.e., E. coli) bacteria, respectively (Prince et al., 2011). These receptors recognize pathogen-associated molecular patterns present on invading 


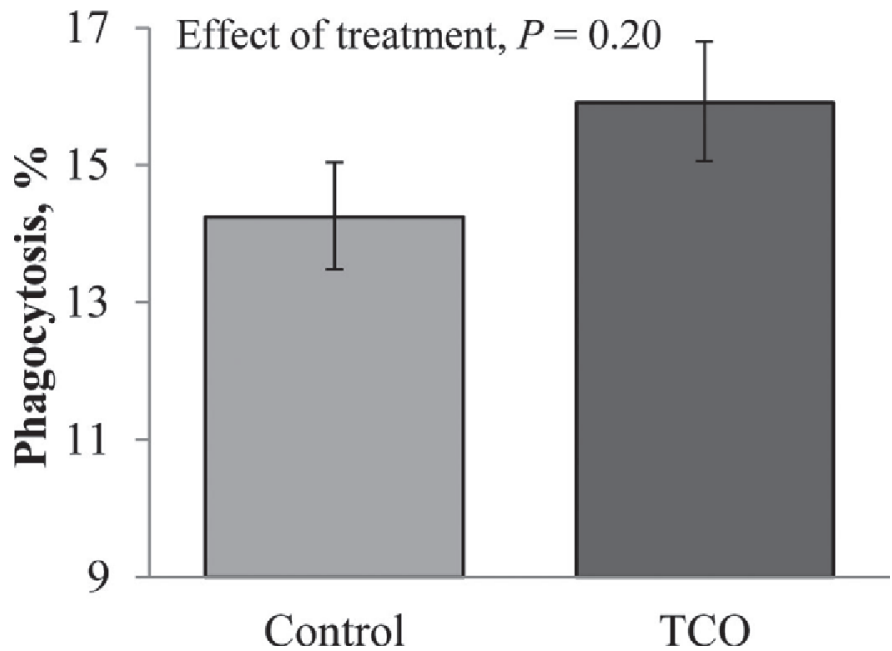

Figure 1. Percent phagocytosis of PMNL incubated with 0 (control) or $0.01 \%$ of cold-pressed terpeneless orange oil (TCO) in vitro.

microorganisms and can generate a wide range of effects on PMNL including migration, activation of signaling factors, cytokine production, reactive-oxygen-species generation, priming, receptor expression, phagocytosis, degranulation, and programmed cell death (Prince et al., 2011; Thomas and Schroder, 2013). In the current study, expression of TLR 4 was not affected by treatment $(\mathrm{FC}=1.13)$, but TLR2 was downregulated in PMNL incubated with TCO $(\mathrm{FC}=-2.14, P=0.03)$. Smith-Palmer et al. (1998) observed that gram-negative bacteria were less susceptible to the microbial effect of plant essential oils and hypothesized that the outer membrane of gram-negative bacteria is a strong permeability barrier restricting the entry of hydrophobic compounds. Studies at the University of Arkansas using the same product as in the current study (TCO) and from the same provider reported that $0.1 \%$ TCO reduced the growth of Staph. aureus (gram positive, Muthaiyan et al., 2012b) but failed to inhibit the growth of 11 serotypes and strains of Salmonella (gram negative) when used in 4 serial dilutions starting with $1 \%$ TCO (O'Bryan et al., 2008). Therefore, TCO may have a more potent antimicrobial effect against gram-positive bacteria via the downregulation of TLR2 rather than to gram-negative bacteria but warrants further investigation.

The recognition of pathogen-associated molecular patterns by TLR- 4 present on the surface of PMNL elicits a cascade of signaling events that enhance the synthesis of proinflammatory cytokines and proinflammatory mediators (Prince et al., 2011; Thomas and Schroder, 2013). Toll-like receptors activate the NF- $\kappa B$ proinflammatory signaling cascade that encompasses
A

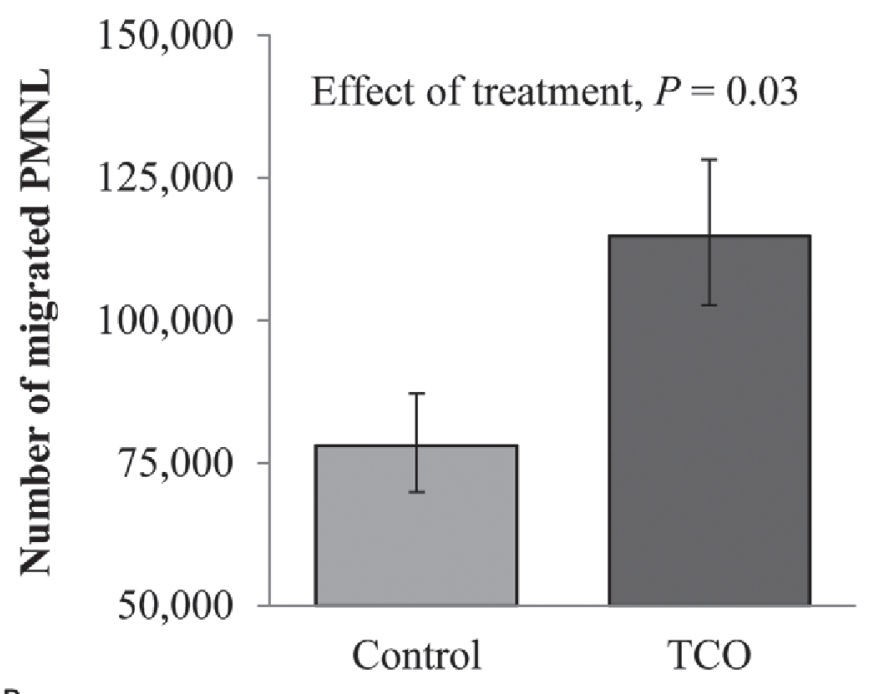

B

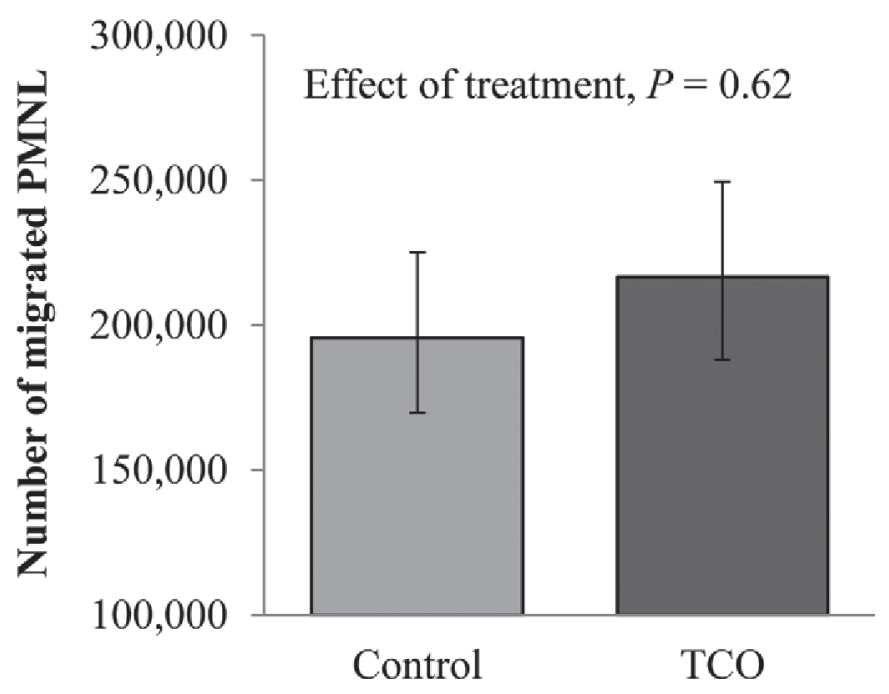

Figure 2. Number of PMNL migrating in response to chemokine IL-8 (A) and C5a (B) after incubation with either 0 (control) or $0.01 \%$ of cold-pressed terpeneless orange oil (TCO) in vitro.

the activation of MyD88, TRAF-6, IRAK-1, and the IKK complex that ultimately leads to secretion of proinflammatory cytokines TNF- $\alpha$, IL-6, and IL-1 $\beta$ (Akira et al., 2001). In the current study the expression of IRAK1 and TRAF6 was not altered by TCO. To the contrary, NFKBIA, the gene coding for the I $\kappa \mathrm{B} \alpha$ protein, was downregulated by $\mathrm{TCO}(\mathrm{FC}=-1.82$, $P=0.05)$. This downregulation would be expected considering that NF- $\kappa \mathrm{B}$ binds to the $\mathrm{I} \kappa \mathrm{B}$ promoter to activate its transcription; therefore, a decrease in NFK$B I A$ expression should be associated with a decrease in $\mathrm{NF}-\kappa \mathrm{B}$ activation, resulting in an overall decrease in expression of proinflammatory genes (Camargo et al., 
Table 1. Expression of genes in PMNL incubated with 0 (control) or $0.01 \%$ of cold-pressed terpeneless citrus oil (TCO) in vitro

\begin{tabular}{|c|c|c|c|c|}
\hline Symbol & Name & $\begin{array}{c}\text { Fold- } \\
\text { change }^{1}\end{array}$ & $P$-value & CI \\
\hline \multicolumn{5}{|c|}{$\begin{array}{l}\text { Adhesion molecule and pattern } \\
\text { recognition receptor }\end{array}$} \\
\hline TLR4 & Toll-like receptor 4 & 1.13 & 0.57 & -0.98 to 1.30 \\
\hline$S E L L$ & L-Selectin & -1.20 & 0.50 & -1.00 to -1.44 \\
\hline \multicolumn{5}{|c|}{ Signaling factors } \\
\hline TRAF6 & Tumor-necrosis-factor receptor-associated factor 6 & -1.11 & 0.72 & -0.92 to -1.33 \\
\hline \multicolumn{5}{|c|}{ Cytokine production } \\
\hline$I L 1 B$ & IL-1, $\beta$ & -2.16 & 0.02 & -1.82 to -2.55 \\
\hline IL 8 & IL-8 & 1.93 & 0.08 & 1.56 to 2.39 \\
\hline IL 10 & IL-10 & -3.78 & $<0.01$ & -3.13 to -4.58 \\
\hline$T N F A$ & Tumor necrosis factor $\alpha$ & -9.43 & $<0.01$ & -7.28 to -12.22 \\
\hline
\end{tabular}

${ }^{1}$ Correspond to the fold change $\left(2^{-\Delta \Delta \mathrm{Cq}}\right)$ of TCO versus control. Positive value is upregulation and negative is downregulation of a given gene in PMNL incubated with $0.01 \%$ TCO compared with control PMNL. Cq = quantification cycle.

2010). Furthermore, our results showed a downregulation of $I L 1 B(\mathrm{FC}=-2.16, P=0.02)$ and TNFA $(\mathrm{FC}$ $=-9.43, P<0.01)$, encoding for the proinflammatory cytokines IL1- $\beta$ and TNF- $\alpha$, respectively, and TCO did not alter TNF- $\alpha$ production in the spent media of PMNL (29.6 vs. $35.3 \pm 4.73 \mathrm{pg} / \mu \mathrm{L}$, TCO and control, respectively, $P=0.42$ ). However, these results conflict with the downregulation of $\operatorname{IL10}(\mathrm{FC}=-3.78, P<$ 0.01), a known antiinflammatory cytokine. The overall downregulation of proinflammatory genes in the current study indicates that TCO may have an antiinflammatory effect on PMNL transcripts and that TCO does not mount a proinflammatory response.

To kill invading microorganisms, PMNL secrete several potentially harmful substances during the inflammatory response. Among these, the protein lysozyme, coded by the gene $L Y Z$, has a strong antimicrobial effect via degrading the bacteria cell wall (Amulic et al., 2012). In the current study, expression of $L Y Z$ was not affected by the incubation of PMNL with TCO. During phagocytosis, the reactive oxygen cascade results in the production of reactive oxygen species such as superoxide anion and $\mathrm{H}_{2} \mathrm{O}_{2}$ that aid in the killing of engulfed microorganisms (Paape et al., 2003). Superoxide dismutase 2 is an enzyme encoded by SOD2 that converts superoxide anion to $\mathrm{H}_{2} \mathrm{O}_{2}$ in the mitochondria. In the current study, expression of SOD2 tended $(P=0.08)$ to be downregulated in PMNL incubated with TCO (FC $=-1.57$ ), whereas respiratory burst was not measured. Results indicate that TCO does not significantly alter transcripts involved in phagocytosis and respiratory burst of nonstimulated bovine blood PMNL in vitro.

\section{CONCLUSIONS}

Incubation of PMNL with TCO increased chemotactic capability in vitro, whereas PMNL phagocytosis was unchanged. The expression of genes involved in the proinflammatory response was primarily downregulated; however, TNF- $\alpha$ production was not altered by TCO when compared with controls. Results show that $0.01 \%$ TCO does not impair the function of PMNL in vitro, indicating that TCO inhibits bacterial growth without negatively altering PMNL function. Future studies investigating the use of TCO as an alternative therapy for treatment of mastitis, including dose and duration, for cows during lactation are warranted.

\section{ACKNOWLEDGMENTS}

This study was funded via the Maryland Agricultural Experiment Station. The authors acknowledge the Agricultural Research Service-USDA staff in Beltsville, Maryland, for their assistance with animal care and data collection. Gratitude in extended to Brian Barrows, Alejandro Almario, and Cori Williford, from University of Maryland, for their laboratory assistance. Firmenich Citrus Center (Safety Harbor, FL) is gratefully acknowledged for providing the citrus oil fraction.

\section{REFERENCES}

Akira, S., K. Takeda, and T. Kaisho. 2001. Toll-like receptors: Critical proteins linking innate and acquired immunity. Nat. Immunol. 2:675-680. 
Alzoreky, N. S., and K. Nakahara. 2003. Antimicrobial activity of extracts from some edible plants commonly consumed in Asia. Int. J. Food Microbiol. 80:223-230.

Amulic, B., C. Cazalet, G. L. Hayes, K. D. Metzler, and A. Zychlinsky. 2012. Neutrophil function: From mechanisms to disease. Annu. Rev. Immunol. 30:459-489.

Bannantine, J. P., S. C. Olsen, M. E. Kehrli Jr., T. B. Stanton, E. Casas, D. L. Whipple, and K. A. Zuelke. 2013. High-impact animal health research conducted at the USDA's National Animal Disease Center. Vet. Microbiol. 165:224-233.

Burvenich, C., D. D. Bannerman, J. Lippolis, L. Peelman, B. Nonnecke, M. Kehrli Jr., and M. Paape. 2007. Cumulative physiological events influence the inflammatory response of the bovine udder to Escherichia coli infections during the transition period. J. Dairy Sci. 90:E39-E54.

Burvenich, C., V. Van Merris, J. Mehrzad, A. Diez-Fraile, and L. Duchateau. 2003. Severity of E. coli mastitis is mainly determined by cow factors. Vet. Res. 34:521-564.

Byrne, M. B., Y. Kimura, A. Kapoor, Y. He, K. S. Mattam, K. M. Hasan, L. N. Olson, F. Wang, P. J. Kenis, and C. V. Rao. 2014. Oscillatory behavior of neutrophils under opposing chemoattractant gradients supports a winner-take-all mechanism. PLoS ONE 9:e85726.

Caldefie-Chézet, F., C. Fusillier, T. Jarde, H. Laroye, M. Damez, M. P. Vasson, and J. Guillot. 2006. Potential anti-inflammatory effects of Melaleuca alternifolia essential oil on human peripheral blood leukocytes. Phytother. Res. 20:364-370.

Callaway, T. R., J. A. Carroll, J. D. Arthington, T. S. Edrington, R. C. Anderson, M. L. Rossman, M. A. Carr, K. J. Genovese, S. C. Ricke, and P. Crandall. 2011. Orange peel products can reduce Salmonella populations in ruminants. Foodborne Pathog. Dis. 8:1071-1075.

Camargo, A., J. Ruano, J. M. Fernandez, L. D. Parnell, A. Jimenez, M. Santos-Gonzalez, C. Marin, P. Perez-Martinez, M. Uceda, and J. Lopez-Miranda. 2010. Gene expression changes in mononuclear cells in patients with metabolic syndrome after acute intake of phenol-rich virgin olive oil. BMC Genomics 11:253.

Crandall, P. G., S. C. Ricke, C. A. O'Bryan, and N. M. Parrish. 2012 In vitro effects of citrus oils against Mycobacterium tuberculosis and non-tuberculous mycobacteria of clinical importance. J. Environ. Sci. Health B 47:736-741.

Fisher, K., and C. Phillips. 2008. Potential antimicrobial uses of essential oils in food: Is citrus the answer? Trends Food Sci. Technol. 19:156-164.

Foxman, E. F., J. J. Campbell, and E. C. Butcher. 1997. Multistep navigation and the combinatorial control of leukocyte chemotaxis. J. Cell Biol. 139:1349-1360.

Fratini, F., S. Casella, M. Leonardi, F. Pisseri, V. V. Ebani, L. Pistelli, and L. Pistelli. 2014. Antibacterial activity of essential oils, their blends and mixtures of their main constituents against some strains supporting livestock mastitis. Fitoterapia 96:1-7.

Freshney, R. 1987. Culture of Animal Cells: A Manual for Basic Technique. Alan R. Liss Inc., New York, NY.

Hart, P., C. Brand, C. Carson, T. Riley, R. Prager, and J. FinlayJones. 2000. Terpinen-4-ol, the main component of the essential oil of Melaleuca alternifolia (tea tree oil), suppresses inflammatory mediator production by activated human monocytes. Inflamm. Res. 49:619-626.

Hirota, R., N. N. Roger, H. Nakamura, H. S. Song, M. Sawamura, and N. Suganuma. 2010. Anti-inflammatory effects of limonene from Yuzu (Citrus junos Tanaka) essential oil on eosinophils. J. Food Sci. 75:H87-H92.

Jacob, M. E., T. R. Callaway, and T. Nagaraja. 2009. Dietary interactions and interventions affecting Escherichia coli O157 colonization and shedding in cattle. Foodborne Pathog. Dis. 6:785-792.

Janovick-Guretzky, N. A., H. M. Dann, D. B. Carlson, M. R. Murphy, J. J. Loor, and J. K. Drackley. 2007. Housekeeping gene expression in bovine liver is affected by physiological state, feed intake, and dietary treatment. J. Dairy Sci. 90:2246-2252.

Juergens, U. R., T. Engelen, K. Racké, M. Stöber, A. Gillissen, and H. Vetter. 2004. Inhibitory activity of 1, 8-cineol (eucalyptol) on cy- tokine production in cultured human lymphocytes and monocytes. Pulm. Pharmacol. Ther. 17:281-287.

Kacem, R., and Z. Meraihi. 2009. The effect of essential oil extracted from Nigella sativa (L.) seeds on human neutrophil functions. Nat. Prod. Res. 23:1168-1175.

Kadegowda, A. K. G., M. Bionaz, B. Thering, L. S. Piperova, R. A. Erdman, and J. J. Loor. 2009. Identification of internal control genes for quantitative polymerase chain reaction in mammary tissue of lactating cows receiving lipid supplements. J. Dairy Sci. 92:2007-2019.

Kehrli, M. E.. Jr., and D. E. Shuster. 1994. Factors affecting milk somatic cells and their role in health of the bovine mammary gland. J. Dairy Sci. 77:619-627.

Kirchner, J., and J. M. Miller. 1952. Preparation of terpeneless essential oils. A chromatographic process. Ind. Eng. Chem. 44:318-321.

Kummer, R., F. C. Fachini-Queiroz, C. F. Estevão-Silva, R. Grespan, E. L. Silva, C. A. Bersani-Amado, and R. K. N. Cuman. 2013. Evaluation of anti-inflammatory activity of Citrus latifolia Tanaka essential oil and limonene in experimental mouse models. Evid. Based Complement. Alternat. Med. http://dx.doi. org $/ 10.1155 / 2013 / 859083$

Livak, K. J., and T. D. Schmittgen. 2001. Analysis of relative gene expression data using real-time quantitative PCR and the 2(-Delta Delta $\mathrm{C}(\mathrm{T})$ ) method. Methods 25:402-408.

Mayadas, T. N., X. Cullere, and C. A. Lowell. 2014. The multifaceted functions of neutrophils. Annu. Rev. Pathol. 9:181-218.

Moufida, S., and B. Marzouk. 2003. Biochemical characterization of blood orange, sweet orange, lemon, bergamot and bitter orange. Phytochemistry 62:1283-1289.

Moyes, K. M., J. K. Drackley, D. E. Morin, and J. J. Loor. 2010. Greater expression of TLR2, TLR4, and IL6 due to negative energy balance is associated with lower expression of $H L A-D R A$ and $H L A-A$ in bovine blood neutrophils after intramammary mastitis challenge with Streptococcus uberis. Funct. Integr. Genomics 10:53-61.

Moyes, K. M., J. K. Drackley, J. L. Salak-Johnson, D. E. Morin, J. C. Hope, and J. J. Loor. 2009. Dietary-induced negative energy balance has minimal effects on innate immunity during a Streptococcus uberis mastitis challenge in dairy cows during midlactation. J. Dairy Sci. 92:4301-4316.

Muthaiyan, A., D. Biswas, P. G. Crandall, B. J. Wilkinson, and S. C. Ricke. 2012a. Application of orange essential oil as an antistaphylococcal agent in a dressing model. BMC Complement. Altern. Med. 12:125

Muthaiyan, A., E. M. Martin, S. Natesan, P. G. Crandall, B. J. Wilkinson, and S. C. Ricke. 2012b. Antimicrobial effect and mode of action of terpeneless cold-pressed Valencia orange essential oil on methicillin-resistant Staphylococcus aureus. J. Appl. Microbiol. 112:1020-1033.

Nannapaneni, R., V. I. Chalova, P. G. Crandall, S. C. Ricke, M. G. Johnson, and C. A. O'Bryan. 2009. Campylobacter and Arcobacter species sensitivity to commercial orange oil fractions. Int. J. Food Microbiol. 129:43-49.

Nannapaneni, R., A. Muthaiyan, P. G. Crandall, M. G. Johnson, C. A. O'Bryan, V. I. Chalova, T. R. Callaway, J. A. Carroll, J. D. Arthington, and D. J. Nisbet. 2008. Antimicrobial activity of commercial citrus-based natural extracts against Escherichia coli O157:H7 isolates and mutant strains. Foodborne Pathog. Dis. 5:695-699.

Nickerson, S., and S. Oliver. 2014. Review: How well have United States dairy producers adopted mastitis-control technologies for reducing herd somatic cell counts and improving milk quality? Prof. Anim. Sci. 30:115-124.

O'Bryan, C. A., P. Crandall, V. Chalova, and S. Ricke. 2008. Orange essential oils antimicrobial activities against Salmonella spp. J. Food Sci. 73:M264-M267.

Paape, M. J., D. D. Bannerman, X. Zhao, and J.-W. Lee. 2003. The bovine neutrophil: Structure and function in blood and milk. Vet. Res. 34:597-627.

Pittman, C. I., S. Pendleton, B. Bisha, C. A. O'Bryan, K. E. Belk, L. Goodridge, P. G. Crandall, and S. C. Ricke. 2011. Activity of cit- 
rus essential oils against Escherichia coli O157:H7 and Salmonella spp. and effects on beef subprimal cuts under refrigeration. J. Food Sci. 76:M433-M438.

Plastridge, W. N. 1958. Bovine mastitis: A review. J. Dairy Sci. 41:1141-1181.

Prince, L. R., M. K. Whyte, I. Sabroe, and L. C. Parker. 2011. The role of TLRs in neutrophil activation. Curr. Opin. Pharmacol. 11:397-403.

Shannon, E. M., S. R. Milillo, M. G. Johnson, and S. C. Ricke. 2011 Efficacy of cold-pressed terpeneless Valencia oil and its primary components on inhibition of Listeria species by direct contact and exposure to vapors. J. Food Sci. 76:M500-M503.

Smith-Palmer, A., J. Stewart, and L. Fyfe. 1998. Antimicrobial properties of plant essential oils and essences against five important food-borne pathogens. Lett. Appl. Microbiol. 26:118-122.
Sordillo, L. M. 2005. Factors affecting mammary gland immunity and mastitis susceptibility. Livest. Prod. Sci. 98:89-99.

Thomas, C. J., and K. Schroder. 2013. Pattern recognition receptor function in neutrophils. Trends Immunol. 34:317-328.

Vandesompele, J., P. K. De, F. Pattyn, B. Poppe, R. N. Van, P. A. De, and F. Speleman. 2002. Accurate normalization of real-time quantitative RT-PCR data by geometric averaging of multiple internal control genes. Genome Biol. 3:RESEARCH0034. http://dx.doi. org/10.1186/gb-2002-3-7-research0034.

Williams, M. R., V. Azcutia, G. Newton, P. Alcaide, and F. W. Luscinskas. 2011. Emerging mechanisms of neutrophil recruitment across endothelium. Trends Immunol. 32:461-469. 